\title{
Iron Speciation of Cored Sediments from Erhai Lake, SW China
}

\author{
GUODONG ZHENG ${ }^{1}$, SHENG XU², KATSUHIKO SUZUKI ${ }^{3}$, \\ XIANGXIAN MA ${ }^{1}$, QIAOHUI FAN ${ }^{1}$
}

${ }^{1}$ Key Lab. Petrol. Res. Gansu Province, Northwest Institute of Eco-Environment \& Resources, Lanzhou 730000, China (gdzhbi@mail.iggcas.ac.cn)

${ }^{2}$ Inst Surface-Earth Syst Sci. Tianjin University, Tianjin 300072, China (sheng.xu@tju.edu.cn)

${ }^{3}$ IFREE, JAMSTEC, Yokosuka 237-0061, Japan

(katz@jamstec.go.jp)

Various geochemical indicators can be used to identify past depositional environments, for which modern sediments in lakes are usually ideal candidates. Six sub samples were obtained from one core collected using a gravity corer from the Erhai Lake, one of fresh water lakes along the Yuanjiang fault zone in Yunnan Province SW China and analyzed for iron species using Mossbauer Spectroscopy. The $120 \mathrm{~cm}$ core has a distinct lithological boundary at a depth of about $70 \mathrm{~cm}$. Four iron species were identified as paramagnetic $\mathrm{Fe}^{3+}$, superparamagnetic $\mathrm{Fe}^{3+}$. hematite $\mathrm{Fe}^{3+}$, and paramagnetic $\mathrm{Fe}^{2+}$. With increasing burial depth, hematite $\left(\mathrm{Fe}_{2} \mathrm{O}_{3}\right)$ decreased, especially below depth great than $25 \mathrm{~cm}$, and finally disappeared at depth around $95 \mathrm{~cm}$. The summed paramagnetic $\mathrm{Fe}^{3+}$ (superparamagnetic $\mathrm{Fe}^{3+}$ and paramagnetic $\mathrm{Fe}^{3+}$ ) did not change as much, only exhibiting a slightly decrease at depths greater than $75 \mathrm{~cm}$, about $5 \mathrm{~cm}$ beneath the lithological boundary within the core. The intensity of paramagnetic high-spine $\mathrm{Fe}^{2+}$ increased with depth. These vertical variations were in harmony with organic geochemical parameters such as total organic matter (TOC) content, H-index and O-index, indicating that reducing conditions are strongly intensified in the sediments below $70 \mathrm{~cm}$. The geological background, organic geochemistry and ${ }^{14} \mathrm{C}$ data combined with the present Mossbauer spectroscopic study give a strong indication that the redox environment of the Erhai Lake probably shifted rather rapidly shifted from a deep reducing to a shallow oxic state about $2 \mathrm{ka}$ ago, which could be caused by either strong earthquake events or anthropogenic activities.

In addition, a proposed method to quantitatively identify sedimentary pyrite was developed by using ${ }^{57} \mathrm{Fe}$ Mossbauer spectroscopy and X-ray absorption near-edge structure (XANES) with a series of acidic pre-treatments. This method can be used to measure pyrite in aquatic sediments, especially when the pyrite contents are very low and the particles of pyrite are small or the crystallinity is low, even in amorphous status.

\section{References}

Zheng et el., 2001, Appl. Geoch 16, 1201-1213

Zheng et al., 2006, JRUC 269, 43-50 